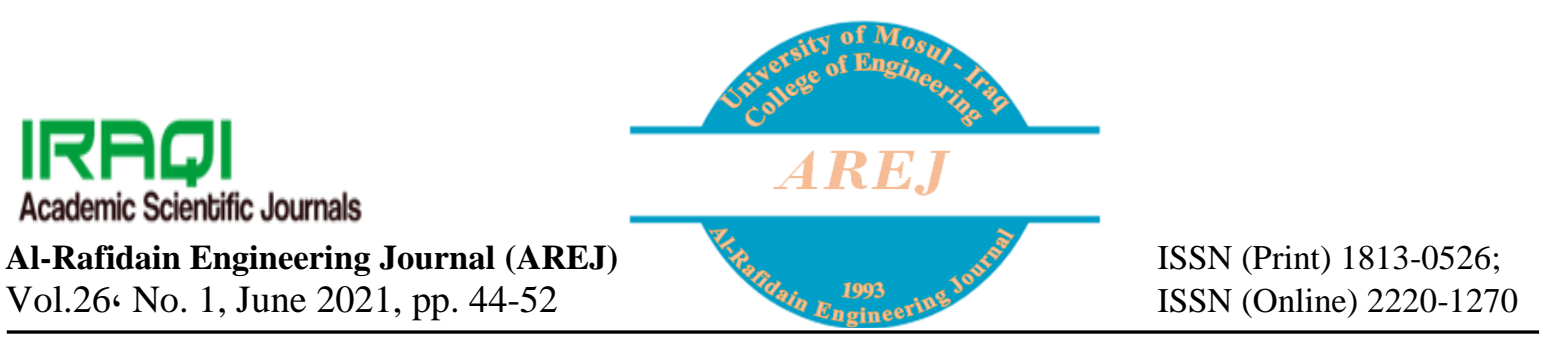

\title{
Evaluation of Acceleration Noise Parameter as a Traffic Flow Performance Indicator for Multi-Lane Urban Highways
}

\author{
Mohammed H. Naef \\ civil.mohammed2008@gmail.com \\ Abdulkhalik M. Al-Taei \\ Abdelkhaleq@uomosul.edu.iq \\ Civil Engineering Department, Collage of Engineering, University of Mosul
}

Received: $22 / 8 / 2020$

Accepted: $20 / 1 / 2021$

\begin{abstract}
This study was conducted to use acceleration noise as an alternative measure to the level of service on multilane urban highways located within Kirkuk City. The study provides a simplified and easy way to evaluate the level of service (LOS) instead of the extended methodology proposed by the Highway Capacity Manual (HCM-2010). Ten (10) multi-lane urban segments were chosen within the study area for collecting the required field data. Moving Vehicle Method $(M V M)$ with a digital camera equipped with a built-in GPS receiver were utilized to collect field data. Acceleration noise takes the form of an exponential function $\left(y=e^{x}\right)$ when associated with traffic flow variables (traffic volume, density, and speed). Final results have revealed that acceleration noise could be used as a surrogate measuring the level of service for multi-lane urban highways within the ranges of the level of service LOS A-LOS C.
\end{abstract}

Keywords:

Acceleration Noise; Kirkuk City; Level of Service; Multi-Lane Urban Highways: Moving Vehicle Method

https://rengj.mosuljournals.com

Email: alrafidain_engjournal1@uomosul.edu.iq

\section{INTRODUCTION}

Acceleration Noise can be defined as the second derivative of the speed or standard deviation of the vehicle-acceleration, including the acceleration and/or deceleration [1]. It represents the mathematical sum of two components of noise experienced by drivers, namely [2];

1. Natural-Noise: represents the change in the acceleration either as an increase or decrease of the vehicle speed as a result of the impact of road's geometric characteristics such as the presence of traffic hump, surface friction, narrow lateral clearance, and bridges or subways...., etc.; and;

2. Traffic-Noise: is an accelerationchange induced by the driver of the vehicle due to the proximity to other vehicles in the traffic stream.

Acceleration noise was first proposed and discussed as a parameter that describing the characteristics of road-traffic-drivers/vehicles under different conditions [1].

It is considered as a factor to measure the quality and smoothness of traffic flow for two significant reasons [3]
1. It depends on the three basic elements of traffic such as driver, traffic condition, and geometric parameters of the road and;

2 . Because it is considered as a measure of the smoothness of traffic flow within the traffic stream and a good qualitative indicator within the limits of the quantitative criteria.

The noticeable increase in the number of vehicles in general and private-sector vehicles in particular during the past two decades put a shadow over the road patterns in Kirkuk City as given by (Central Statistics OrganizationIraq)[4]. Traffic density in Iraqi roads reached about 115 vehicles $/ \mathrm{km}$, according to the report of the (Central Statistics Organization-Iraq)[4] for the year 2016. The percentage of increase in the number of the recorded vehicles in Kirkuk Governorate for (2014-2016) years was about 15 percent (i.e., 7.5 percent per year) according to (Central Statistics Organization-Iraq)[4]. The number of vehicles owned by individuals has increased to (176 vehicles per 1000 capita (2016)) due to the relative increase in income of 
individuals and the availability of imported vehicles. The individuals start depending on their cars to carry out their activities without relying on public transportation, which has put a burden on existing road patterns and prompted the relevant authorities to increase the capacity of existing roads and develop new roadways. There is an imperative need to evaluate the quality of existing road patterns, identify the causes of traffic congestion, and the strategies in which these problems can be resolved. The approved methodology recommended by Highway Capacity Manual[5] is an extended method that needs to collect a lot of data and time-consuming when performing the analysis to evaluate multi-lane urban highways. Therefore, this study suggested a simplified, easy, and applicable method within the Level of Service LOS (A-C) ranges to assess the quality of the existing network's roads without referring to the (HCM-2010) methodology.

Babu and Pattnaik, (1997)[6] examined the relationship between many speed-variation measures including acceleration noise, standard deviation of speed, coefficient of variation of speed and traffic congestion. Urban roads with different geometric have been studied. They found that acceleration noise has often linear relationship with all basic traffic parameters. Also, Acceleration noise can be used to determine the different (LOS) for urban roads even more for mixed traffic conditions.

Greenwood et al. (2007)[2] developed a model to estimate congestion impacts on fuel consumptions based on acceleration noise and vehicle emissions. They concluded that:

1. Acceleration noise was the best measure to quantify traffic congestion.

2. The relationship between mean speed and acceleration noise is linear.

Ko et al. (2009)[7] studied the relationship between acceleration noise and roadway characteristics on freeway corridors with different number of lanes, speed limit 55 and 65 $\mathrm{mph}$, grade, and curvature, they found that:

1. There is no significance difference between three-lane and four-lane roadways sections on acceleration noise. Otherwise, twolane roadways evidence to substantially increase acceleration noise under LOS (A-D) thresholds.

2. The degree of curvature directly proportional with acceleration noise. The major effect occurred at free flow speed or LOS A

Salini et al. (2019)[8] stated that acceleration noise was a good parameter for the representation of passenger car unit (PCU) values on urban roads.

\section{OBJECTIVES OF THE RESEARCH}

The primery objectives of this study can be summarize as below:

1. To link the acceleration noise parameter with traffic density ranges at each level of (LOS) ranges. In other words, to measure the level of service in terms of this parameter;

2. To provide a simplified method for traffic engineers who are looking for (LOS) on arterial urban roads. This method would allow them to propose a maintenance plan to reduce congestion and increase the quality of service of multi-lane urban highways.

\section{RESEARCH METHODOLOGY}

\subsection{Study Area}

Kirkuk City has chosen as the study area for this research. Kirkuk governorate located in the North of Iraq ( $\left.35^{\circ} 28^{\prime} 0^{\prime \prime} \mathrm{N}, 4^{\circ} 19^{\prime} 0^{\prime \prime} \mathrm{E}\right)$ to about $(238 \mathrm{~km})$ from the north of the capital Baghdad [9]. The CBD area of Kirkuk City is characterized by a high traffic density due to the presence of commercial activities and government offices. Ten (10) segments of six-lane divided urban roads located in the city center of Kirkuk selected for data collection of this research (see Fig. 1), and Table (1) is showing the North-East Latitude and departures of the sample segments included in this study. General geometric data for the segments studied acquired from the Master Plan of Kirkuk City with the contribution of the municipality of Kirkuk City. Other geometric data obtained from GIS Software. The length of each segment studied is more than the minimum requirements by the (HCM-2010) methodology that have been specified to be $762 \mathrm{~m}$ (2500 ft.) and located more than $400 \mathrm{~m}$ (0.25 mile) away from the intersections.

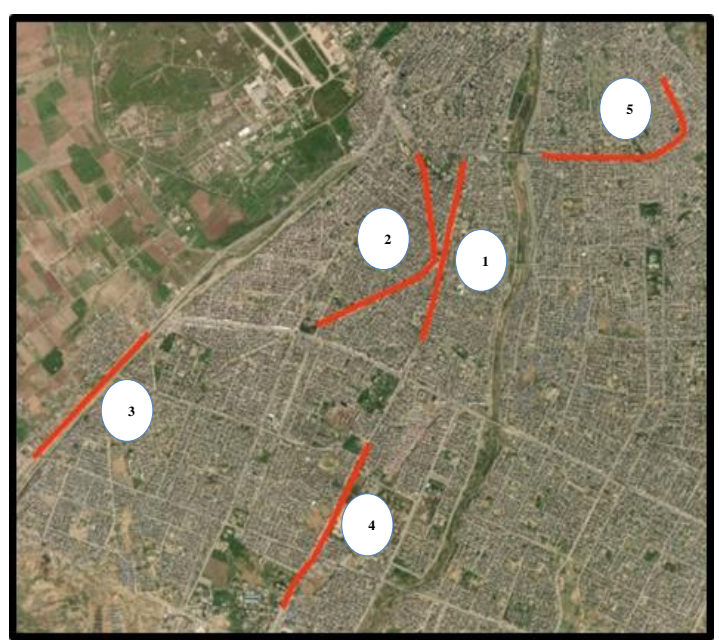

Fig. 1: Study Area with Selected Segments-Kirkuk City (Google Maps, 2018)

Table 1: Latitude and Longitude for the Ten Segments Studied 


\begin{tabular}{|c|c|c|c|}
\hline No & Segment Name & South-North & North-South \\
\hline 1 & $\begin{array}{l}\text { Baghdad } \\
\text { Road }\end{array}$ & $\begin{array}{l}35^{\circ} 25^{\prime} 46.511^{\prime \prime} \mathrm{N} \\
44^{\circ} 22^{\prime} 31.088^{\prime \prime} \mathrm{E}\end{array}$ & $\begin{array}{l}35^{\circ} 26^{\prime} 50.894^{\prime \prime} \mathrm{N} \\
44^{\circ} 22^{\prime} 51.102^{\prime \prime} \mathrm{E}\end{array}$ \\
\hline 2 & $\begin{array}{l}\text { Al-Quds } \\
\text { Street }\end{array}$ & $\begin{array}{l}35^{\circ} 25^{\prime} 56.720^{\prime \prime} \mathrm{N} \\
44^{\circ} 21^{\prime} 49.413^{\prime \prime} \mathrm{E}\end{array}$ & $\begin{array}{l}35^{\circ} 26^{\prime} 55.601^{\prime \prime ~ N ~} \\
44^{\circ} 22^{\prime} 32.891^{\prime \prime} \mathrm{E}\end{array}$ \\
\hline 3 & $\begin{array}{l}\text { Airport } \\
\text { Road }\end{array}$ & $\begin{array}{c}35^{\circ} 25^{\prime} 2.654^{\prime \prime} \mathrm{N} \\
44^{\circ} 19^{\prime} 20.074^{\prime \prime} \mathrm{E}\end{array}$ & $\begin{array}{c}35^{\circ} 25^{\prime} 44.779^{\prime \prime} \mathrm{N} \\
44^{\circ} 20^{\prime} 6.620^{\prime \prime} \mathrm{E}\end{array}$ \\
\hline 4 & $\begin{array}{l}\text { University } \\
\text { Road }\end{array}$ & $\begin{array}{r}35^{\circ} 24^{\prime} 3.303^{\prime \prime} \mathrm{N} \\
44^{\circ} 21^{\prime} 26.024^{\prime \prime} \mathrm{E}\end{array}$ & $\begin{array}{l}35^{\circ} 24^{\prime} 56.61^{\prime \prime} \mathrm{N} \\
44^{\circ} 22^{\prime} 0.809^{\prime \prime} \mathrm{E}\end{array}$ \\
\hline & & East-West & West-East \\
\hline 5 & $\begin{array}{l}\text { Kirkuk- } \\
\text { Sulaymaniyah } \\
\text { Road }\end{array}$ & $\begin{array}{c}35^{\circ} 27^{\prime} 2.971^{\prime \prime} \mathrm{N} \\
44^{\circ} 23^{\prime} 36.978^{\prime \prime} \mathrm{E}\end{array}$ & $\begin{array}{l}35^{\circ} 27^{\prime} 33.731^{\prime \prime} \mathrm{N} \\
44^{\circ} 24^{\prime} 35.019^{\prime \prime} \mathrm{E}\end{array}$ \\
\hline
\end{tabular}

\subsection{Traffic Data Collection}

Traffic data obtained during working days using video-recording technology for each segment at various times. This method allows many events to be observed simultaneously. Video recording techniques have been widely used due to their capability to collect data of all traffic flow characteristics together and simplify data extraction at both microscopic and macroscopic levels [10]. Data collected by using digital dash camera equipped with built-in GPS receiver which records location and speed second-by-second along with the video recording time. The camera is attached to the front of the windscreen of test car and operated by a vehicle cigar plug as shown in Figure (2). Required traffic parameters extracted manually from those videos by replaying them for better accuracy. Ten repeated runs made for each segment to ensure the data obtained is more reliable.[11] showed that six test runs are adequate and accurate to unbiased estimate of the measuring variables in each direction of traffic.

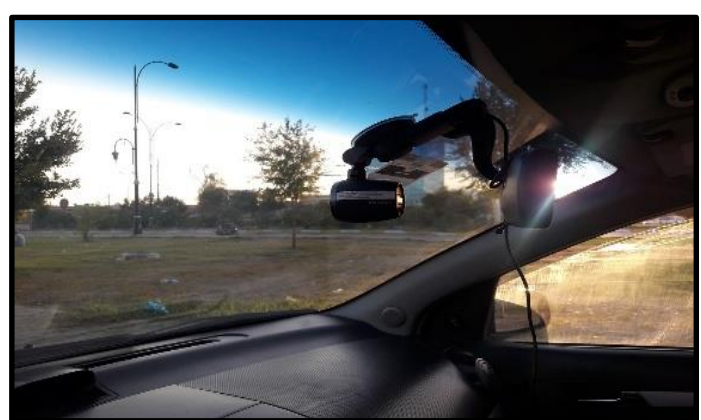

Fig. 2: Dash Camera Mounted in Windshield of Test Car

Moving Vehicle Method (i.e., MVM) is a method given to measure traffic speeds and flows by observations made by the procedure developed by[12] for urban traffic measurement. It is an effective technique commonly used for estimating the average traffic flow, speed, and travel time across a road segment.

Assume that trip runs started from east to west. Hourly volume (V) for the westbound direction for example can be gotten from the Equation (1)

Where:

$$
\mathrm{V}_{\mathrm{w}}=\frac{60\left(\mathrm{~N}_{\mathrm{e}}+\mathrm{O}_{\mathrm{w}}-\mathrm{P}_{\mathrm{w}}\right)}{\mathrm{T}_{\mathrm{e}}+\mathrm{T}_{\mathrm{w}}}
$$

1. Travel time in minutes while traveling east $\left(T_{e}\right)$;

2. Travel time in minutes while traveling west

$\left(\mathrm{T}_{\mathrm{w}}\right)$;

3. The number of vehicles met (opposing flow) while the test car is traveling east $\left(\mathrm{N}_{\mathrm{e}}\right)$;

4. Total vehicles (overtaking) passing the test vehicle while traveling west, which means traveling westbound $\left(\mathrm{O}_{\mathrm{w}}\right)$;

5. Total Vehicles that passed by the test car while it was traveling west, which means traveling westbound $\left(\mathrm{P}_{\mathrm{w}}\right)$;

The average travel time in the westbound direction is obtaining from Equation (2).

$$
\overline{\mathrm{T}}_{\mathrm{w}}=\mathrm{T}_{\mathrm{w}}-\left(\frac{60\left(\mathrm{O}_{\mathrm{w}}-\mathrm{P}_{\mathrm{w}}\right)}{\mathrm{V}_{\mathrm{w}}}\right)
$$

To obtain the average space mean speed along the segment in the westbound direction $\left(\mathrm{S}_{\mathrm{w}}\right)$. Length of segment (L) divided by average travel time $\left(\overline{\mathrm{T}}_{\mathrm{w}}\right)$ in the same direction as the following (see Equ. 3):

$$
S_{w}=\frac{60 L}{\mathrm{~T} \overline{\mathrm{w}}}
$$

Finally, traffic density (D) in a westbound direction obtained from Equation (4) by dividing westbound traffic volume by space mean speed in the same direction [13].

$$
\mathrm{D}_{\mathrm{w}}=\frac{\mathrm{v}_{\mathrm{w}}}{\mathrm{S}_{\mathrm{w}}}
$$

Table (2) shows the computation sheet of moving vehicle method.

Table 2: Moving Car Computation Data Sheet

(Kirkuk-Sulaymaniyah Road) (E-W) Direction

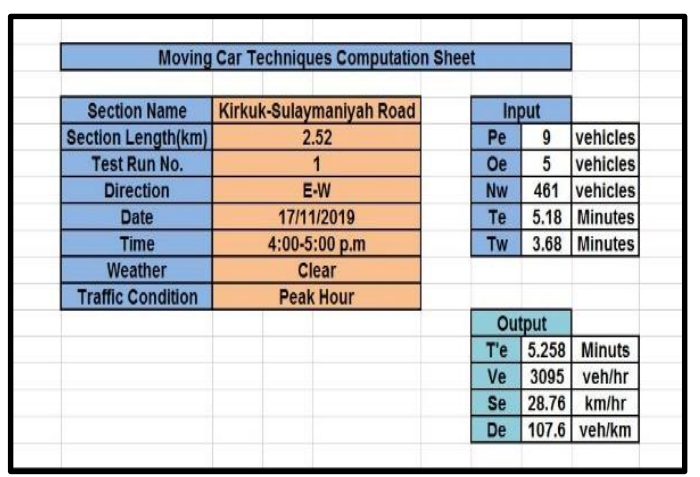

\subsection{Acceleration Noise Data Collection}

Acceleration noise data collected for each investigated segment using the same moving vehicle techniques as previously explained. The data obtained from round trips made for the same ten (10) studied segments. As mentioned earlier, ten runs made for each segment (i.e., total of 100 runs for studied segments). Considerations taken when collecting data to be during workdays and 
daylight times started from (7:00 A.M. to 5:00 P.M.) within October and November months. Acceleration noise computed by using an equation driven by [14], which based on speed-time diagram and it is adaptable to reduce and analyze of data:

Where:

$$
\sigma=\left[\frac{(\Delta u)^{2}}{T} \sum_{i=1}^{k} \frac{n i^{2}}{\Delta t i}-\left(\frac{V_{t}-V_{0}}{T}\right)^{2}\right]^{1 / 2}
$$

$\sigma$ : Acceleration noise $\left(\mathrm{ft} / \mathrm{sec}^{2}\right)$;

$\Delta \mathrm{u}$ : Constant increment of speed-change;

$\Delta$ ti: Time interval in (second) for a change in speed.

ni: Integer denoting the number of speedchange at constant increment $\Delta \mathrm{u}$ (taken $2 \mathrm{mph}$ $(3.2 \mathrm{~km} / \mathrm{hr}$ ) for this study) over a period of time (30 seconds);

$\mathrm{V}_{\mathrm{t}}$ : The speed of test vehicle at the start of the trip;

$V_{0}$ : The speed of test vehicle at the end of trip; and

T: Total time motion which equal to $\Sigma \Delta$ ti.

Table (3) shows calculation method of acceleration noise values.

Table 3: Calculation Method of Acceleration Noise Data (Baghdad Road Segment)

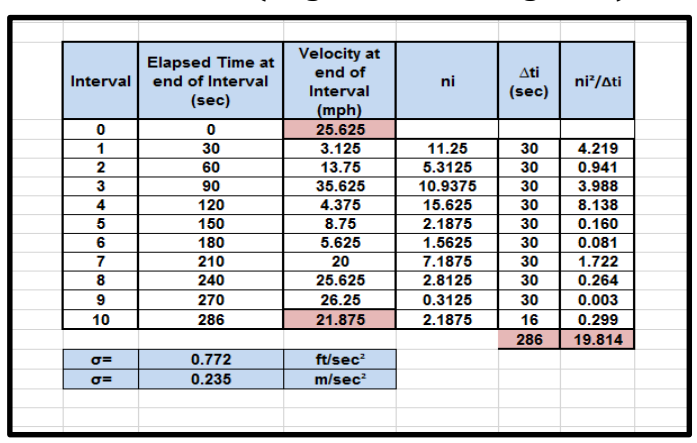

\subsection{Capacity Computation}

Observed capacity for segments studied were estimated by using fundamental diagram method which based on existence relationship between three variables (i.e., flow, average speed of traffic stream, and density), [15].The method has been assessed as a good method for estimating capacity in practice [16]. The capacity of segments calculated graphically by deriving the function of flow-density relationship. The highest value that can be obtained from the curve is by putting the first derivative equal to (zero), which represents the observed capacity of the segments investigated. Measured capacity equal to $1607 \mathrm{pc} / \mathrm{km} / \mathrm{ln}$ for all segments since this study taken all segments as a one sample including composite traffic. This value was adopted in the study to represent the existing prevailing conditions.

\subsection{Computation of LOS}

The level of service is a qualitative measure of the segment facility[17]. It is commonly used as a measure of effectiveness (i.e., MOE'S) alternative for evaluation of traffic congestion that might be developed at any segment or intersegment approach. LOS describes a range of traffic quality based on letters grading scale from LOS A up to LOS F[5]. The quality of the traffic stream decreases when LOS changes from (A-F). For uninterrupted multilane highways, LOS is determined on the basis of traffic density values instead of a speed that remains approximately unchanged through a wide-range of flow rates (HCM- 2010). The impact of the interaction and proximity of vehicles to each other in the traffic stream could be measured by traffic density (HCM-2010). Three traffic parameters used to describe LOS for multilane highways as performance fundamental traffic-flow characteristics. The relationship combined these parameters is shown in the equation below:

$$
\mathrm{D}=\frac{\mathrm{V}_{\mathrm{p}}}{\mathrm{S}}
$$

Where:

D: traffic density (pc/km/ln);

$\mathrm{V}_{\mathrm{p}}$ : demand flow-rate (pc/hr./ln); and

$\mathrm{S}$ : average speed of traffic stream $(\mathrm{km} / \mathrm{hr})$.

Free-Flow-Speed (FFS) represents a mean speed of vehicles on the road segments that are far away from intersection effects (uninterrupted flow) measured within the light to moderate traffic density conditions[18]. For multilane highways, FFS has measured under traffic flow-rate up to $1400 \mathrm{pc} / \mathrm{hr} / \mathrm{ln}$ (HCM-2010). It is a considerable variable used with adjusted flow-rate to determine the LOS of the roadway. Free-flow-speed (FFS) influenced by environmental conditions and geometric features of the road [19]. The HCM-2010 methodology offered an indirect method for estimating the freeflow speed (FFS) of the multilane highway segment. The offered method based on the correction of the free-flow-speed at base condition abbreviated as (BFFS) using equation (7) from (HCM-2010). The (BFFS) estimated in this study for each segment studied by taken posted speed plus $8 \mathrm{~km} / \mathrm{hr}(5 \mathrm{mi} / \mathrm{hr})$ for speed limit $80 \mathrm{~km} / \mathrm{hr}(50$ $\mathrm{mi} / \mathrm{hr})$ and higher and plus $11 \mathrm{~km} / \mathrm{hr}(7 \mathrm{mi} / \mathrm{hr})$ for speed limit less than $80 \mathrm{~km} / \mathrm{hr}(50 \mathrm{mi} / \mathrm{hr})$ (HCM2010). The methodology is given by HCM-2010 for computing LOS on multilane highways at specified geometric data and various traffic conditions.

$$
F F S=B F F S-f_{l w}-f_{l c}-f_{m}-f_{A}
$$

Where:-

$\mathrm{FFS}=$ Free Flow Speed of segment $(\mathrm{km} / \mathrm{hr})$; 
BFFS $=$ Base Free Flow Speed of segment $(\mathrm{km} / \mathrm{hr})$; $\mathrm{f}_{\mathrm{lw}}=$ correction factor of width of lane, calculated from (Chapter 14, exhibit 14-8) in (HCM-2010); $\mathrm{f}_{\mathrm{lc}}=$ correction factor of total lateral clearance (left and right clearance), calculated from exhibit (149) in (HCM-2010);

$\mathrm{f}_{\mathrm{m}}=$ correction factor for type of median, calculated from (Chapter 14, exhibit 14-10) in (HCM-2010); and,

$\mathrm{f}_{\mathrm{A}}=$ correction factor for density of access points, calculated from (Chapter 14, exhibit 14-11) in (HCM-2010).

Computed traffic volume from equation (1) must be converted to demand flow rate $\left(V_{p}\right)$ for each segment by using equation (8) from (HCM2010) below:

Where:

$$
v_{P}=\frac{V}{P H F * N * f_{H V} * f_{P}}
$$

$\mathrm{V}=$ traffic volume (veh/hr) which obtained from equation (1);

$\mathrm{PHF}=$ peak hour factor;

$\mathrm{N}=$ number of lanes;

$\mathrm{f}_{\mathrm{HV}}=$ correction factor of heavy vehicles; and $\mathrm{f}_{\mathrm{P}}=$ correction factor of the driver's population (0.85 or 1.0) according to (HCM-2010), taken (1.0) for this study since the driver is familiar (from the target community).

Correction factor of heavy vehicles can be calculated from the equation (9) which adopted in (HCM-2010).

$$
f_{H V}=\frac{1}{1+P_{T}\left(E_{T}-1\right)+P_{R}\left(E_{R}-1\right)}
$$

Where:

$\mathrm{P}_{\mathrm{T}}=$ percentage of heavy vehicles in the traffic stream;

$\mathrm{E}_{\mathrm{T}}=$ equivalent of a passenger car for one heavy vehicle, taken (1.5) for this study since the segments considered as level terrain (HCM-2010, Chapter 14, exhibit 14-12).

$P_{R}=$ percentage of recreation vehicles;

$E_{R}=$ equivalent of passenger car for one recreation vehicles.

Since there are no recreation vehicles in the traffic stream of the study area, then the factors $\left(P_{R}\right.$ and $\left.E_{R}\right)$ substituted by zero in this study.

After completion the requirements of computing of LOS according to (HCM-2010) methodology, LOS for each segment studied at each test run computed by using simplified formula made by (MS-Excel-2016 version) as shown in the Table (4). The made formula sheet automatically calculated LOS by entering the required variables.
Table 4: Simplified Worksheet Used for Calculating LOS (Baghdad Road Segment)

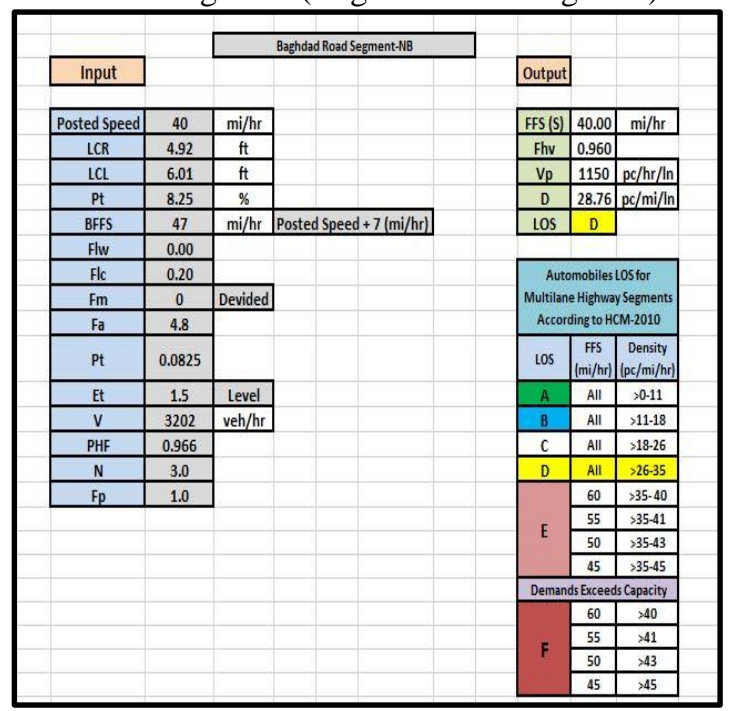

\section{RESULTS AND DISCUSSIONS}

\subsection{Normality Test of Acceleration Noise}

There are several statistical methods recommended to determine whether or not the data for a random variable is following the normal distribution. The most widely used tests for assessing normality is Kolmogorov-Smirnov (KS) with Lilliefors Correction Test [20]. The results of test carried out on the measured acceleration noise data from ten segments studied (i.e., 100 observations) demonstrated that, the acceleration noise is following or drawn from the normal distribution at confidence interval (95\%). This result is concluded as the (P-Value) which equals to $(0.144)$ is more than the significance level $(\alpha=$ 0.05 ) for Kolmogorov-Smirnov (K-S) test, and K$\mathrm{S}$ statistic equal to $(0.078)$ which is less than critical value from Kolmogorov-Smirnov table for $(\mathrm{N}=100, \alpha=0.05)$ equal to $(0.136)$ as is shown in Table (5) below according to [21].

Table 5: Normality Test using KolmogorovSmirnov with Lilliefors Correction Test (SPSS V.26)

\begin{tabular}{|c|c|c|c|c|}
\hline \multicolumn{4}{|c|}{ Test of Normality } \\
\hline \multirow{2}{*}{$\begin{array}{c}\text { Tested } \\
\text { Variable }\end{array}$} & \multicolumn{4}{|c|}{$\begin{array}{c}\text { Kolmogorov-Smirnov with Lilliefors } \\
\text { Correction Test }\end{array}$} \\
\cline { 2 - 5 } & $\mathrm{df}$ & $\begin{array}{c}\text { K-S } \\
\text { Statistic }\end{array}$ & $\begin{array}{c}\text { K-S } \\
\text { Table }\end{array}$ & P-Value \\
\hline $\begin{array}{c}\text { Acceleration } \\
\text { Noise } \mathrm{m} / \mathrm{s} 2\end{array}$ & 100 & 0.078 & 0.136 & 0.144 \\
\hline
\end{tabular}




\subsection{Effect of Traffic Volume on} Transformed Acceleration Noise

Using the curve fitting process by [22] to select the best model for the relationship of acceleration noise as a dependent variable and traffic volume as independent at significance level $(\alpha=0.05)$. The results of the analysis show that the S-curve is the best model according to a good correlation coefficient of $(\mathbf{R}=\mathbf{0 . 8 2 6})$. The resulting model has taken the form of an exponential function (i.e., $\mathrm{y}=\mathrm{e}^{\mathrm{x}}$ ) and treated as a dependent variable or/and as a natural logarithm (Ln), so the transformation of the dependent variable data into a natural logarithm can yield better results. Data was transformed and the curve estimation performed to select the best model. The results revealed that, the polynomial quadratic relationship represents the best model with less scatter and a good correlation coefficient of ( $\mathbf{R}=\mathbf{0 . 8 2 9})$ as shown in the Figure (3).

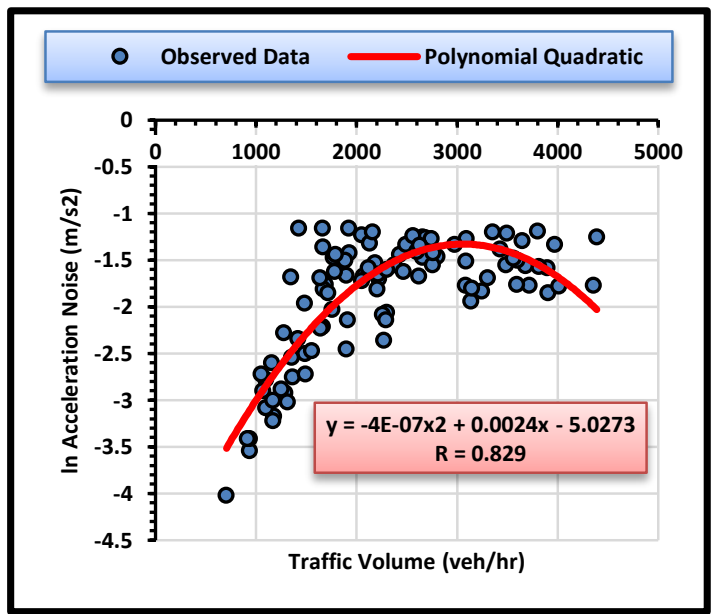

Fig. 3: Effect of Traffic Volume on the

Transformed Acceleration Noise on Multi-Lanes Arterial Roads

The relationship has slightly improved after the transformation of the acceleration noise data. The polynomial quadratic relationship was therefore adopted in this study. Table (6) display model summary for the quadratic relationship between $\ln$ acceleration noise and traffic volume.

Table 6: Model Summary of the Relationship between $\ln$ Acceleration Noise and Traffic

$*: \mathrm{F}(0.05,1,99)=3.95$
4.3. Effect of Average Speed on Transformed Acceleration Noise

\begin{tabular}{|c|c|c|c|c|c|}
\hline \multicolumn{7}{|c|}{ Model Summary } \\
\hline $\begin{array}{c}\text { Dependent } \\
\text { Variables }\end{array}$ & $\mathrm{R}$ & $\mathrm{R}^{2}$ & F-stat. & F-tab. & $\begin{array}{c}\mathrm{P} \text { - } \\
\text { value }\end{array}$ \\
\hline $\begin{array}{c}\text { In } \\
\text { Acceleration } \\
\text { Noise m/s2 }\end{array}$ & 0.829 & 0.687 & 106.22 & $3.95^{*}$ & 0.00 \\
\hline \multicolumn{6}{|c|}{ Independent Variable: Traffic Volume veh/hr } \\
\hline \multicolumn{6}{|c|}{ Regression analysis conducted using }
\end{tabular}
curve fiting techniques provided by (SPSS V.26) software. The Exponential shape was chosen as the best model with a correlation coefficient of ( $\mathbf{R = 0 . 8 0 7 )}$ whereas the dispersion is high around the regression line. As the same procedure followed in the effect of traffic volume on acceleration noise, data transforming required to test the best fit model since the exponential model has taken the natural algorithm of acceleration noise as a dependent variable. After the transformation of acceleration noise data and performing the analysis, the best fit curve resulted from the analysis was a polynomial quadratic with $(\mathbf{R}=\mathbf{0 . 8 7 2})$ and less scatter around the regression line (see Fig. 4). Model accuracy has improved by about eight percent when transforming the acceleration noise data to the natural logarithm (ln). Therefore, this model adapted to represent the relationship between the speed and the acceleration noise. The summary of selected model can be seen in Table (7).

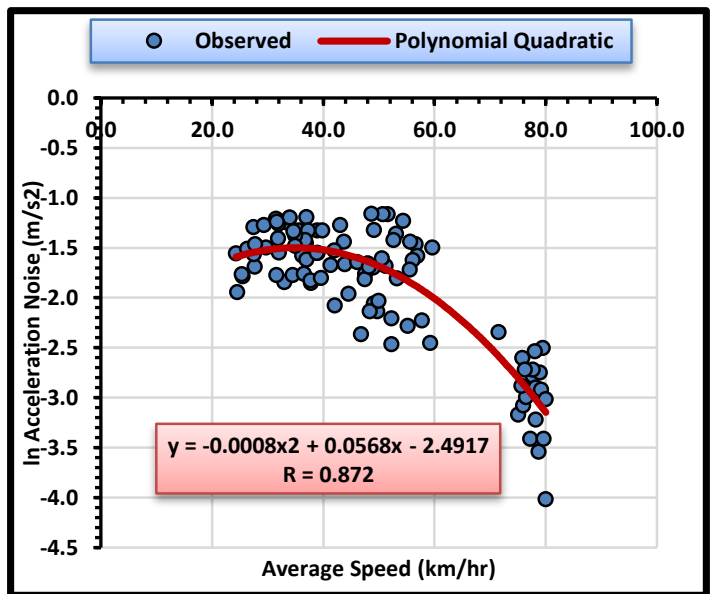

Fig. 4: Effect of Average Speed on the

Transformed Acceleration Noise on Multi-Lanes Arterial Roads

Table 7: Model Summary of the Relationship between $\ln$ Acceleration Noise and Average

$*: \mathrm{F}(0.05,1,99)=3.95$ 


\begin{tabular}{|c|c|c|c|c|c|}
\hline \multicolumn{7}{|c|}{ Model Summary } \\
\hline $\begin{array}{c}\text { Dependent } \\
\text { Variables }\end{array}$ & $R$ & $R^{2}$ & Fstat. & Ftab. & $\begin{array}{c}\text { P- } \\
\text { value }\end{array}$ \\
\hline $\begin{array}{c}\text { In } \\
\text { Acceleration } \\
\text { Noise m/s2 }\end{array}$ & 0.872 & 0.76 & 153.61 & $3.95^{*}$ & 0.00 \\
\hline \multicolumn{2}{|c|}{ Independent Variable: Average Speed (km/hr.) } \\
\hline
\end{tabular}

4.4. Effect of Traffic Density on

Transformed Acceleration Noise

Regression analysis carried out to examine the effects of the traffic density on the acceleration noise. By using (SPSS V.26) software with curve fitting procedure, the results revealed that the S-curve represent the best fit model while with high dispersion around the regression line. The S-curve was chosen as the best model with $(\mathbf{R}=\mathbf{0 . 8 8 6})$, but it deals with acceleration noise as a natural logarithm (ln). As mentioned earlier on the return of acceleration noise data to its natural logarithm. The transformation was carried out and the related analysis is checked once more. The polynomial quadratic relationship was identified as the best model after the transformation. The coefficient of correlation for the quadratic model obtained is $(\mathbf{R}=\mathbf{0 . 8 7 7})$. The relationship slightly decreased whereas the dispersion around regression line has decreased too as shown in Figure (5). The polynomial quadratic relationship has been adopted in this study. Table (8) displays the summary of selected model.

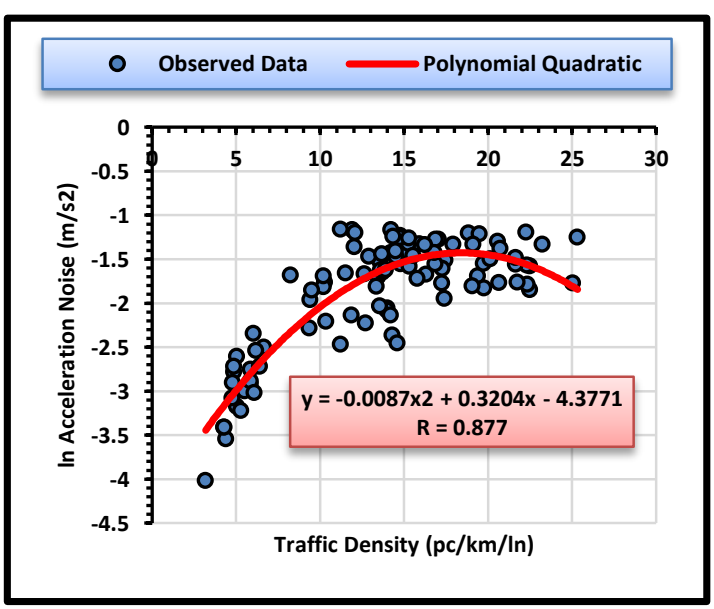

Fig. 5: Effect of Traffic Density on the

Transformed Acceleration Noise on Multi-Lanes Arterial Roads

Table 8: Model Summary of the Relationship between ln Acceleration Noise and Traffic Density

$*: \mathrm{F}(0.05,1,99)=3.95$

\subsection{LOS Thresholds defined by Transformed Acceleration Noise and Traffic Density}

\begin{tabular}{|c|c|c|c|c|c|}
\hline \multicolumn{7}{|c|}{ Model Summary } \\
\hline $\begin{array}{c}\text { Dependent } \\
\text { Variables }\end{array}$ & $R$ & $R^{2}$ & F-stat. & F-tab. & $\begin{array}{c}\text { P- } \\
\text { value }\end{array}$ \\
\hline $\begin{array}{c}\text { In } \\
\text { Acceleration } \\
\text { Noise m/s2 }\end{array}$ & 0.87 & 0.76 & 162.2 & $3.95^{*}$ & 0.00 \\
\hline \multicolumn{7}{|c|}{ Independent Variable: Traffic Density pc/km } \\
\hline \multicolumn{6}{|c|}{ The methodology of (HCM-2010) }
\end{tabular}

defined LOS on multi-lane urban highways by traffic density. Using the traffic density thresholds from (HCM-2010) at each LOS on the transformed

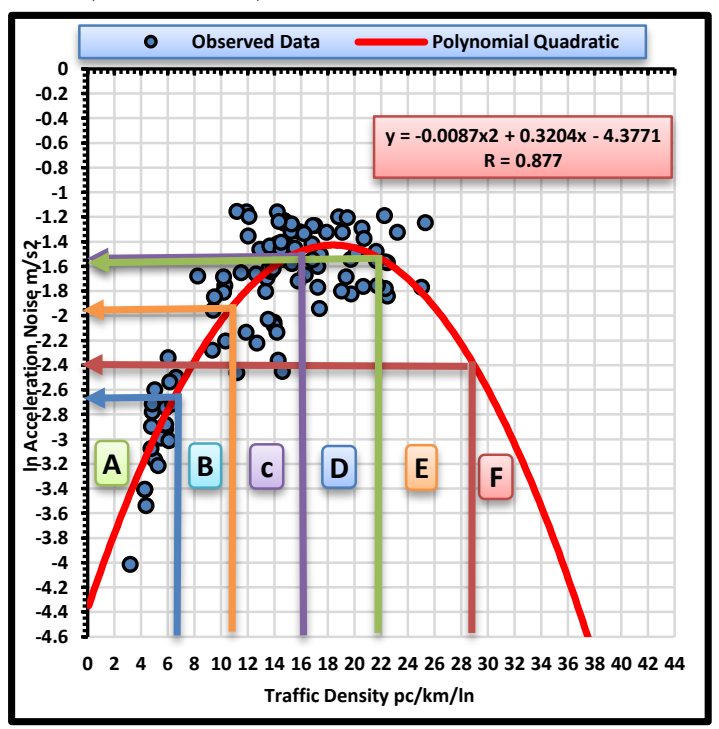

acceleration-density relationship it is possible to derive a new criterion to evaluate the LOS instead of using the (HC-2010) criteria. Figure (6) illustrates a graphical projections of traffic density thresholds to compute the transformed acceleration noise values.

Fig. 6: Graphical Layout of Density Thresholds on Transformed Acceleration Noise-Density Relationship on Multi-Lane Urban Arterials

As shown in Table (9), transformed acceleration noise can very well evaluate multilane urban highways from LOS (A-C) whereas its values start to drop as LOS deteriorates from (DF). The reason for this is that the driver could not maneuver, lane-changing, or increase its speed due to the increased interaction of vehicles in the traffic stream. So, the change in speed is relatively small. As the acceleration noise is directly proportional to the change in speed, it will decrease until it reaches a natural acceleration noise or zero approximately at a high traffic density.

Table 9: Final LOS Thresholds Defined by Transformed Acceleration Noise and Traffic Density 


\begin{tabular}{|c|c|c|c|}
\hline LOS & $\begin{array}{c}\text { Density } \\
\text { Thresholds } \\
\text { (pc/mi//n) } \\
\text { According to } \\
\text { HCM-2010 }\end{array}$ & $\begin{array}{c}\text { Transformed } \\
\text { Density } \\
(\mathrm{pc} / \mathrm{km} / \mathrm{In})\end{array}$ & $\begin{array}{c}\text { LOS Thresholds } \\
\text { defined by } \\
\text { Transformed } \\
\text { Acceleration Noise } \\
\left(\mathrm{m} / \mathrm{s}^{2}\right)^{*}\end{array}$ \\
\hline A & $0-11$ & $0-6.83$ & $4.38-2.60$ \\
\hline B & $11-18$ & $6.83-11.18$ & $2.60-1.88$ \\
\hline C & $18-26$ & $11.18-16.15$ & $1.88-1.47$ \\
\hline D & $26-35$ & $16.15-21.74$ & $1.47-1.52$ \\
\hline E & $35-45$ & $21.74-27.95$ & $1.52-2.22$ \\
\hline F & $>45$ & $>27.95$ & $>2.22$ \\
\hline
\end{tabular}

*: All values of transformed acceleration noise have negative sings

\section{CONCLUSION}

According to the methods of analysis and case study limitations followed in this research, the following conclusions can be drawn out based on the findings of the research:

1. The results emphases that acceleration noise is drawn from a normal distribution and it is taken the form of Exponential Function $\left(\mathrm{y}=\mathrm{e}^{\mathrm{x}}\right)$ when correlated with traffic flow variables.

2 . The quality of the traffic flow for multilane urban highways under LOS (A C) could be better assessed using acceleration noise as an evaluative parameter on multi-lane arterial roads in Kirkuk City.

3. Polynomial Quadratic Shape is the best representative of the relationship between transformed acceleration noise, traffic volume, average speed, traffic density, with high correlation coefficients $(\mathrm{R}=0.829, \mathrm{R}=0.872, \mathrm{R}=$ $0.877)$ respectively on multi-lane arterial roads in Kirkuk City.

\section{ACKNOWLEDGEMENTS}

Authors are willing to acknowledge some offices in Kirkuk City like joint operations command-Kirkuk, Directorate of Kirkuk Municipality, and Directorate of Urban Planning for their support, help, and assistance in performing this study.

\section{REFERENCES}

[1] R. Herman, E. W. Montroll, R. B. Potts, and R. W. Rothery, "Traffic Dynamics:
Analysis of Stability in Car Following," vol. 7, pp. 86-106, 1959.

[2] I. Greenwood, R. Dunn, and R. Raine, "Estimating the Effects of Traffic Congestion on Fuel Consumption and Vehicle Emissions Based on Acceleration Noise," Journal of Transportation Engineering, vol. 133, pp. 96-104, 2007.

[3] D. R. Drew and C. L. Dudek, Investigation of an Internal Energy Model for Evaluating Freeway Level of Service: Texas Transportation Institute, 1965.

[4] C. S. Organization, "Statistics of Private Sector Motorcars That Registered at General Directorate of Traffic," 2016.

[5] HCM 2010 : Highway Capacity Manual: Fifth edition. Washington, D.C. : Transportation Research Board,, 2010.

[6] Y. S. Babu and S. J. Pattnaik, "Acceleration Noise and Level of Service of Urban Roads-A Case Study," vol. 31, pp. 325-342, 1997.

[7] J. Ko, R. Guensler, and M. J. Hunter, "Exploring the Relationship Between Roadway Characteristics and Speed Variation," vol. 2092, pp. 1-10, 2009.

[8] S. Salini, R. Ashalatha, and D. E. Mohan, "Equivalency Factor Based on Acceleration Noise for Mixed Traffic Condition," vol. 5, p. 7, 2019.

[9] Daftlogic.com, "Google Maps Distance Calculator," 12 January 2013. Retrived 26 March 2013.

[10] M. Jabeena, "Comparative Study of Traffic Flow Models And Data Retrieval Methods From Video Graphs," International Journal of Engineering Research and Applications, vol. 3, pp. 1087-1093, 2013.

[11] W. J. Mortimer, "Moving Vehicle Method of Estimating Traffic Volumes and Speeds," vol. 156, pp. 14-26, 1957.

[12] J. G. Wardrop and G. Charlesworth, "A Method of Estimating Speed and Flow of Traffic from a Moving Vehicle," Proceedings of the Institution of Civil Engineers, vol. 3, pp. 158-171, 1954.

[13] N. J. Garber and L. A. Hoel, Traffic \& Highway Engineering-SI Version: Cengage Learning, 2009.

[14] D. R. Drew, C. L. Dudek, and R. R. Keese, "Freeway Level of Service as Described by an Energy-Acceleration Noise Model," 1967.

[15] A. D. May, "Traffic Flow Fundamentals", 1990. 
[16] M. M. Minderhoud, H. Botma, and P. H. Bovy, "Assessment of Roadway Capacity Estimation Methods," Transportation Research Record, vol. 1572, pp. 59-67, 1997.

[17] R. Smit, "An Examination of Congestion in Road Traffic Emission Models and their Application to Urban Road Networks," Griffith University, Australia PhD Thesis, 2006.

[18] U. Abdurrahman, O. C. Puan, and M. N. Ibrahim, "Comparison of Free-Flow Speed Estimation Models," in In National Seminar on Civil Engineering Research (SEPKA), Malaysia., At UTM, Malaysia, 2014, p. 69.
[19] A. T. Ibrahim and F. L. Hall, "Effect of Adverse Weather Conditions on SpeedFlow-Occupancy Relationships", 1994.

[20] Z. Drezner, O. Turel, and D. Zerom, "A Modified Kolmogorov-Smirnov Test for Normality," Communications in Statistics - Simulation and Computation, vol. 39, pp. 693-704, 2010/03/31 2010.

[21] P. O'Connor and A. Kleyner, "Practical Reliability Engineering: John Wiley \& Sons, 2012.

[22] A. IBM Corp, NY, "IBM SPSS Statistics for Windows, Version 26.0," 2018.

\section{تقييم معامل ضوضاء التعجيل المروري كمؤشر لأداء الجريان المروري في الطرق

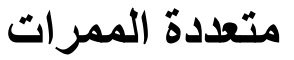

\section{عبد الخالق مال الله محمد الطائي}

Abdelkhaleq@uomosul.edu.iq

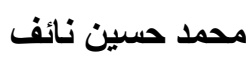

civil.mohammed2008@gmail.com

جامعة الموصل ـ كلية الهندسة ـ قسم الهندسة المدنية

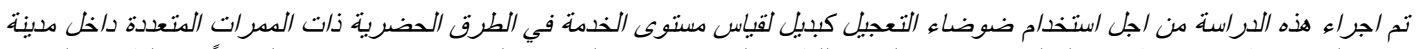

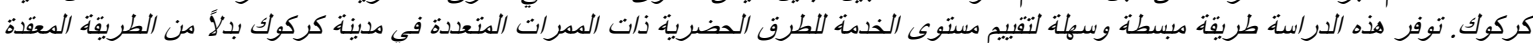

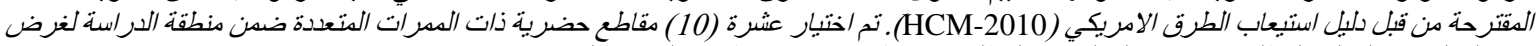

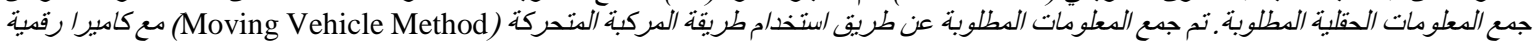

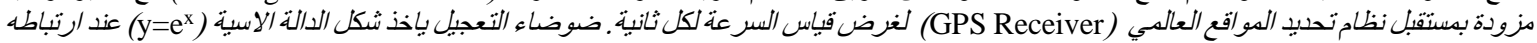

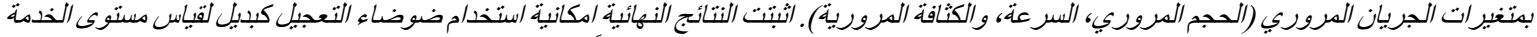

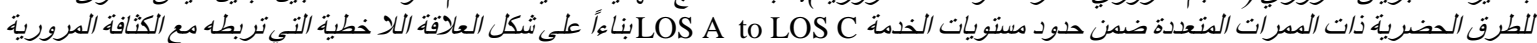
ويقية متغيرات الجريان المروري.

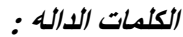
ضوضاء التعجيل، مدينة كركوك، مستوى الخدمة، الطرق متعددة المدرات، طريقة المركبة المتحركة. 